\title{
Different Blood Metabolomics Profiles in Infants Consuming a Meat- or Dairy-Based Complementary Diet
}

\author{
Minghua Tang ${ }^{1, *}$, Nicholas E. Weaver ${ }^{2}$, Lillian M. Berman ${ }^{1}$, Laura D. Brown ${ }^{3}$, Audrey E. Hendricks ${ }^{2}$ and \\ Nancy F. Krebs ${ }^{1}$ (D) \\ 1 Section of Nutrition, Department of Pediatrics, School of Medicine, University of Colorado Anschutz Medical \\ Campus, Aurora, CO 80045, USA; lillian.berman@cuanschutz.edu (L.M.B.); \\ Nancy.Krebs@cuanschutz.edu (N.F.K.) \\ 2 Department of Mathematical and Statistical Sciences, University of Colorado Denver, Denver, CO 80204, USA; \\ NICHOLAS.WEAVER@UCDENVER.EDU (N.E.W.); Audrey.Hendricks@ucdenver.edu (A.E.H.) \\ 3 Section of Neonatology, Department of Pediatrics, School of Medicine, University of Colorado Anschutz \\ Medical Campus, Aurora, CO 80045, USA; laura.brown@cuanschutz.edu \\ * Correspondence: Minghua.Tang@cuanschutz.edu; Tel.: +1-303-724-3248
}

Citation: Tang, M.; Weaver, N.E.; Berman, L.M.; Brown, L.D.; Hendricks, A.E.; Krebs, N.F. Different Blood Metabolomics Profiles in Infants Consuming a Meat- or Dairy-Based Complementary Diet. Nutrients 2021, 13, 388. https:// doi.org/10.3390/nu13020388

Academic Editor: Alaa El-Din A Bekhit

Received: 16 December 2020

Accepted: 23 January 2021

Published: 27 January 2021

Publisher's Note: MDPI stays neutral with regard to jurisdictional claims in published maps and institutional affiliations.

Copyright: (c) 2021 by the authors. Licensee MDPI, Basel, Switzerland. This article is an open access article distributed under the terms and conditions of the Creative Commons Attribution (CC BY) license (https:// creativecommons.org/licenses/by/ $4.0 /)$.

\begin{abstract}
Background: Research is limited in evaluating the mechanisms responsible for infant growth in response to different protein-rich foods; Methods: Targeted and untargeted metabolomics analysis were conducted on serum samples collected from an infant controlled-feeding trial that participants consumed a meat- vs. dairy-based complementary diet from 5 to 12 months of age, and followed up at 24 months. Results: Isoleucine, valine, phenylalanine increased and threonine decreased over time among all participants; Although none of the individual essential amino acids had a significant impact on changes in growth $\mathrm{Z}$ scores from 5 to 12 months, principal component heavily weighted by BCAAs (leucine, isoleucine, valine) and phenylalanine had a positive association with changes in length-for-age $\mathrm{Z}$ score from 5 to 12 months. Concentrations of acylcarnitine-C4, acylcarnitine-C5 and acylcarnitine-C5:1 significantly increased over time with the dietary intervention, but none of the acylcarnitines were associated with infant growth $\mathrm{Z}$ scores. Quantitative trimethylamine $\mathrm{N}$-oxide increased in the meat group from 5 to 12 months; Conclusions: Our findings suggest that increasing total protein intake by providing protein-rich complementary foods was associated with increased concentrations of certain essential amino acids and short-chain acyl-carnitines. The sources of protein-rich foods (e.g., meat vs. dairy) did not appear to differentially impact serum metabolites, and comprehensive mechanistic investigations are needed to identify other contributors or mediators of the diet-induced infant growth trajectories.
\end{abstract}

Keywords: infant nutrition; protein-rich foods; growth; metabolomics

\section{Introduction}

Evidence-based consensus holds that the first year of life is significant for obesity programming, and undesired growth patterns in infancy, namely excessive weight relative to length, are strongly associated with childhood obesity [1]. Nutrition plays a critical role in infant growth trajectories, and dietary protein has been a subject of interest because of its controversial role in infant growth. Some research showed that a high protein intake had been associated with increased overweight risks [2,3], while others showed no growth difference between high- and low protein intakes [4]. Most of these studies focused on the high-protein content of infant formula, and research is limited in the effect of protein source from complementary foods on infant growth, especially among different types of protein-rich foods. Complementary feeding, defined as the addition of solid or semi-solid foods added to infants' diets, usually starts at 5-6 months of age [5]. Dietary diversity significantly increases during this time, including dietary protein source [6]. Research in adults and animal models has shown that types of protein-rich foods can differentially 
impact various health indicators, including insulin resistance [7], cancer risk [8], and bone health [9]. Research is limited, however, in evaluating different types of protein-rich foods during complementary feeding on infant growth and risk of obesity.

Our group recently completed a randomized controlled feeding study that compared two types of protein-rich foods (meat vs. dairy) as the main source of protein from complementary foods between 5 and 12 months of age on infant growth [10]. A follow-up assessment was conducted at 24 months. We discovered that length-for-age Z score (LAZ, linear growth parameter) increased in the meat group and decreased in the dairy group from 5 to 12 months, which resulted in a significant increase of overweight parameter weight-for-length $Z$ score (WLZ) and increased risk of overweight in the dairy group [10]. These divergent growth patterns also persisted at 24 months, one year after the intervention ended [11]. However, mechanisms of the differential growth trajectories in response to dairy vs. meat protein remain unclear. Previous studies showed that a higher protein intake (e.g., infant formula compared to breastmilk) led to increased circulating IGF-1 and insulin [3], which exerted anabolic effects and accelerated weight gain in formula-fed infants. However, IGF-1 did not significantly differ between the two groups of infants in our study [10], when participants consumed the same quantities of protein but from different sources. Emerging research showed that circulating amino acids (e.g., branchedchain amino acids or BCAAs) and acyl-carnitine may also play a role in regulating infant growth and weight gain [12]. The objective of this study was to investigate the mechanisms responsible for different growth trajectories in infants consuming a meat- or dairy-based complementary diet. We used a targeted approach to quantitatively measure amino acid and acyl-carnitine concentrations and an untargeted approach to explore new pathways that might differ between the two study groups.

\section{Materials and Methods}

\subsection{Study Design}

Blood samples were collected from participants in a randomized controlled trial conducted in the metro Denver area in the United States [10]. In brief, full-term infants who were exclusively formula-fed were recruited and randomized to consume a meat- or dairybased complementary diet from 5 to 12 months of life, with meat- or dairy as the primary source of protein of complementary foods. Total protein intake during the intervention was targeted at $15 \%$ of energy or $3 \mathrm{~g} / \mathrm{kg} /$ day, which was higher than the participants' reported habitual intake ( $10 \%$ or $2.1 \mathrm{~g} / \mathrm{kg} / \mathrm{d})$ at 5 months. The meat group consumed pureed beef, pork, and poultry (provided), and the dairy group consumed yogurt and cheese (provided). The same type of cow-milk-based formula was also provided to all participants by the research team. The amount of formula consumed between groups did not significantly differ during the intervention [10]. Both groups consumed comparable amounts of protein and minimal protein from the assigned alternative. Participants' length and weight were assessed every month from baseline (5 months) to the end of the intervention (12 months). Venous blood samples were collected at 5 and 12 months.

One year after the intervention ended at 12 months of age, an observational followup visit was conducted at 24 months with length and weight measurements and blood collections. The purpose of the 24 months follow-up was to determine if there were lasting effects of the dietary intervention from 5-12 months. Blood samples were collected at 5, 12 and 24 months at Children's Hospital Colorado by the Clinical and Translational Research Center pediatric nurses. Up to three attempts were taken to draw blood. If blood could not be obtained by the 3rd attempt, "no blood sample" was noted for the participant's visit. This study was approved by the Colorado Multiple Institutional Review Board and was registered at ClinicalTrials.gov (NCT02142647).

\subsection{Sample Analysis}

Blood samples were centrifuged and serum was stored at -80 degrees $C$ until analysis. Targeted and untargeted metabolomics analyses were conducted by the Metabolomics Core 
Lab at University of Colorado Anschutz Medical Campus. Serum samples were thawed on ice, then $20 \mu \mathrm{L}$ of each was extracted with $480 \mu \mathrm{L}$ of ice-cold lysis/extraction buffer (5:3:2 methanol:acetonitrile:water) containing $2.5 \mu \mathrm{M}$ of stable isotope-labeled amino acid mix (Cambridge Isotope Laboratories, cat no MSK-A2-1.2) and a mix of acylcarnitines (Cambridge Isotope Laboratories, NSK-B-1) diluted 1 to 200 to serve as standards. Samples were extracted and analyzed on a Vanquish ultra-High Performance Liquid Chromatography Work (UHPLC) coupled online to a Q Exactive mass spectrometer (Thermo Scientific) using a high throughput $5 \mathrm{~min} \mathrm{C} 18$ gradient in positive and negative ion modes (separate runs) [13]. All samples were analyzed in one batch. Metabolite assignments for relative and absolute quantification were performed using data analysis software Maven exactly as described [14,15]. For absolute quantification, circulating amino acids, acyl-carnitines and trimethylamine $\mathrm{N}$-oxide (TMAO) concentrations were measured.

\subsection{Statistical Approach}

All statistical analyses were performed using $\mathrm{R}$ (version 3.5.1). For the intervention period (5 to 12 months), the mean change in growth Z-scores (i.e., length-for-age $Z$ score (LAZ), weight-for-length $Z$ score (WLZ), weight-for-age $Z$ score (WAZ), head circumference-for-age $Z$ score (HCAZ)) were regressed in a linear model on diet (dairy or meat protein), change in metabolite concentration, and the interaction between diet and change in metabolite concentration. A separate regression was performed for each of the four growth Z-scores and 32 quantified metabolites resulting in 128 models. This was repeated for the post intervention period (12 to 24 months) to assess whether differences persisted beyond intervention. Next, we assessed the effect of diet on change in metabolite concentrations by modeling change in each of the 32 metabolite concentrations as the outcome and diet as the predictor in a linear regression. Given previous research indicating a strong relationship between TMAO and meat intake, we assessed the relationship with TMAO and the intervention period (5 to 12 months) in the meat only group.

Principal components (PCs) were constructed from the change in standardized metabolite concentrations (12 months -5 months) for the eight essential amino acids identified in the targeted metabolomic assays. As with the individual metabolites, two types of linear regression models were used: (1) PC as the outcome and diet group as the primary predictor, (2) difference in growth Z-scores as the outcome and PCs as the predictors. For the second type of model, interaction between PC and diet group was also assessed. For the untargeted metabolomic compounds, regression analysis was performed as described above using a log-transformation of the change in the metabolite concentration. BenjaminiYekutieli procedures were used to control the false discovery rate (FDR) at 0.05 within each set of hypothesis tests: targeted metabolites with diet, targeted metabolites with growth outcomes, untargeted metabolites with diet, untargeted metabolites with growth outcomes, PCs with diet, and PCs with growth outcomes.

\section{Results}

\subsection{Subjects}

A total of 64 infants completed the dietary intervention ( $n=32$ per group) with weight and length data from 5 to 12 months of age, and 53 infants completed the 24 months observational follow up (Meat group $n=27$, Dairy group $n=26$ ). Blood samples were successfully collected from 51 infants at 5 months (Meat group $n=26$, Dairy group $n=25$ ), 52 infants at 12 months (Meat group $n=26$, Dairy group $n=26$ ) and 36 infants at 24 months (Meat group $n=20$, Dairy group $n=16$ ) (Figure 1). Even though our overall follow-up rate at 24 months was $82 \%$, the lower number of blood samples available for analysis at this time point was secondary to (1) unsuccessful phlebotomy after a maximum of three attempts or (2) parents/caregivers refused to allow for more than one attempt to draw blood. Table 1 summarizes growth $Z$ scores of those participants from whom blood samples were successfully collected at 5,12 and 24 months. There were no significant differences between groups for birth length, sex, maternal BMI or maternal education. Mothers were, 
on average, overweight as defined by BMI between 25 and 29.9. Demographics did not differ between non-participants and participants at 24 months [11]. Consistent with the report of growth Z scores in the parent cohort $(n=64)$ [10], during the intervention, there was a significant group-by-time interaction $(p=0.001)$ of length-for-age $Z$ score (LAZ) from 5 to 12 months, indicating that LAZ increased in the Meat group compared to the dairy group. WAZ increased among all participants from 5 to 12 months. Changes in WAZ and LAZ led to a significant group-by-time interaction $(p=0.02)$ of WLZ. Although participants were off the dietary intervention at 12 months of age and started to consume comparable complementary diets between the meat and dairy groups, these growth trajectories persisted at 24 months (Table 1). These relationships are comparable to the parent cohort that was previously published [11].

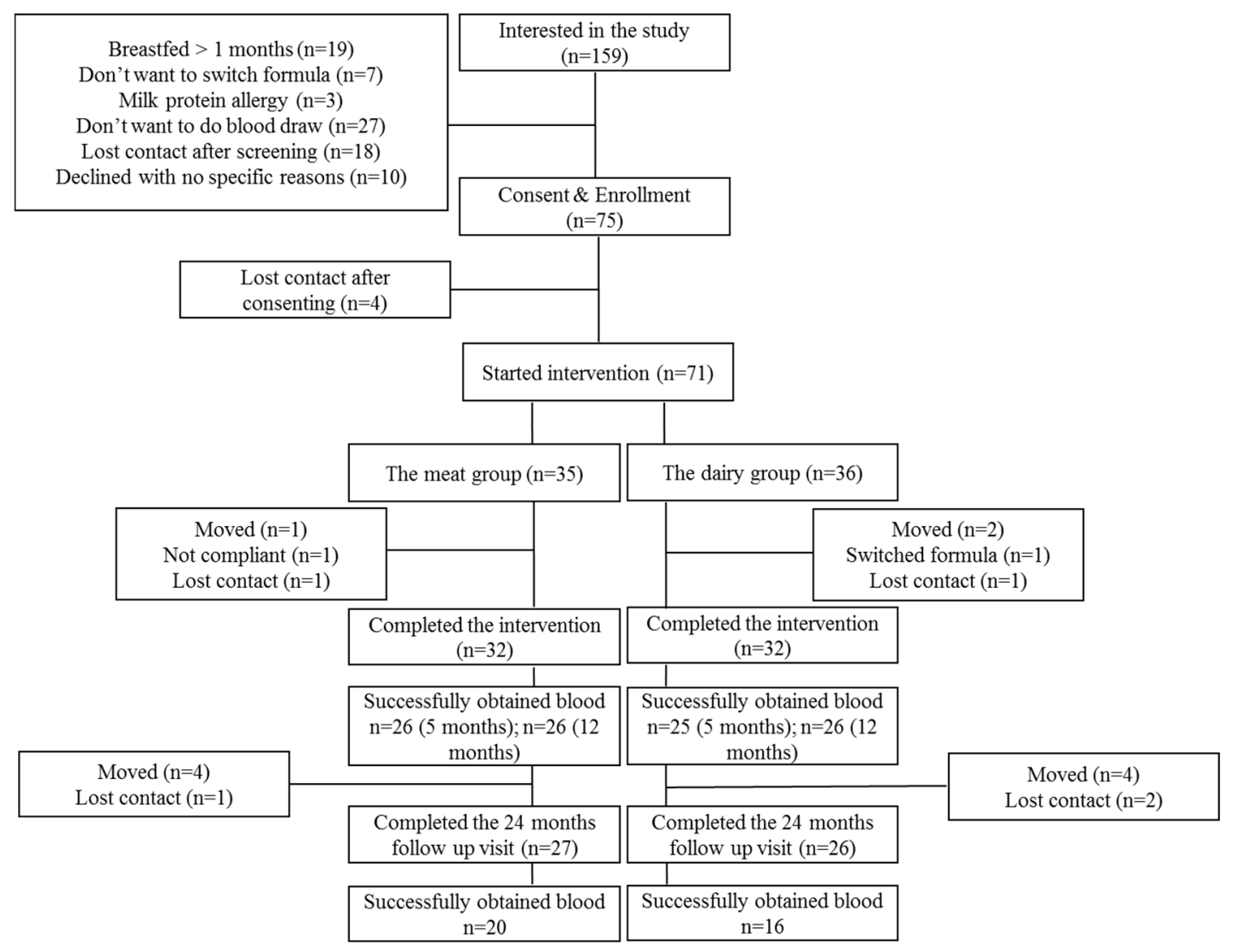

Figure 1. Consort Diagram.

Table 1. Subject characteristics ${ }^{1}$.

\begin{tabular}{cccc}
\hline & Meat Group & Dairy Group & $p$-Value \\
\hline Birth weight $(\mathrm{kg})$ & $3.30 \pm 0.41$ & $3.32 \pm 0.39$ & 0.45 \\
Maternal BMI & $28 \pm 6$ & $28 \pm 7$ & 0.88 \\
5 months LAZ & $-0.19 \pm 0.86$ & $-0.30 \pm 1.02$ & 0.63 \\
5 months WAZ & $-0.03 \pm 0.69$ & $-0.14 \pm 0.82$ & 0.59 \\
5 months WLZ & $0.08 \pm 0.79$ & $0.04 \pm 0.66$ & 0.80 \\
12 months LAZ & $0.14 \pm 0.90$ & $-0.60 \pm 0.91$ & 0.002 \\
12 months WAZ & $0.40 \pm 0.74$ & $0.39 \pm 0.78$ & 0.99 \\
12 months WLZ & $0.95 \pm 0.90$ & $0.33 \pm 0.48$ & 0.04 \\
24 months LAZ & $0.19 \pm 0.62$ & $-0.37 \pm 0.60$ & 0.01 \\
24 months WAZ & $0.40 \pm 0.56$ & $0.31 \pm 0.89$ & 0.65 \\
24 months WLZ & $0.55 \pm 0.99$ & $0.34 \pm 0.70$ & 0.47 \\
\hline
\end{tabular}

${ }^{1}$ Mean $\pm S D,{ }^{2}$ Independent Student's $t$ test. LAZ: length-for-age Z score; WAZ: weight-for-age Z score; WLZ: weight-for-length $\mathrm{Z}$ score. 


\subsection{Essential Amino Acids \\ Concentrations of some essential amino acids, including isoleucine $\left(P_{F D R}=0.0467\right.$, $\left.P_{\text {raw }}=0.0146\right)$, valine $\left(P_{F D R}=0.0011, P_{\text {raw }}=0.0007\right)$, phenylalanine $\left(P_{F D R}=0.0015\right.$, $\left.P_{\text {raw }}=0.0001\right)$ increased and threonine $\left(P_{F D R}=0.0098, P_{\text {raw }}=0.0021\right)$ decreased from 5 to 12 months, without significant differences between diet groups (unadjusted $p$-values of $0.5122,0.6393,0.6848$ and 0.1179 , respectively; Table 2 ). There was no statistically significant effect from 12 to 24 months (Table 2).}

Table 2. Concentrations of serum essential amino acids $(\mu \mathrm{M})$ at 5,12 and 24 months between the meat and dairy groups ${ }^{1}$.

\begin{tabular}{|c|c|c|c|c|c|c|c|c|c|c|}
\hline \multirow[b]{2}{*}{ Amino Acids } & \multirow[b]{2}{*}{$\begin{array}{l}\text { Meat } \\
5 \mathrm{~m}\end{array}$} & \multirow[b]{2}{*}{$\begin{array}{l}\text { Dairy } \\
5 \mathrm{~m}\end{array}$} & \multirow[b]{2}{*}{$\begin{array}{l}\text { Meat } \\
12 \mathrm{~m}\end{array}$} & \multirow[b]{2}{*}{$\begin{array}{l}\text { Dairy } \\
12 \mathrm{~m}\end{array}$} & \multirow[b]{2}{*}{$\begin{array}{l}\text { Meat } \\
24 \mathrm{~m}\end{array}$} & \multirow[b]{2}{*}{$\begin{array}{l}\text { Dairy } \\
24 \mathrm{~m}\end{array}$} & \multicolumn{2}{|c|}{$\begin{array}{c}\text { Meat Vs. Dairy }{ }^{2} \\
p \text {-Value }\end{array}$} & \multicolumn{2}{|c|}{$\begin{array}{c}\text { Change over Time } \\
p \text {-Value }\end{array}$} \\
\hline & & & & & & & $\begin{array}{l}12-5 \mathrm{~m} \\
\text { Model }\end{array}$ & $\begin{array}{c}24-12 \mathrm{~m} \\
\text { Model }\end{array}$ & $\begin{array}{l}12-5 \mathrm{~m} \\
\text { Model }\end{array}$ & $\begin{array}{c}24-12 \mathrm{~m} \\
\text { Model }\end{array}$ \\
\hline L_Histidine & $86.7 \pm 21.3$ & $76.5 \pm 12.3$ & $94.8 \pm 17.02$ & $89.4 \pm 13.4$ & $94.3 \pm 13.1$ & $81.7 \pm 13.3$ & 0.8596 & 0.6570 & 0.0500 & 0.0901 \\
\hline L_Leucine & $83.2 \pm 33.8$ & $74.5 \pm 24.2$ & $93.4 \pm 32.4$ & $101.8 \pm 47.5$ & $66.2 \pm 20.0$ & $65.0 \pm 20.8$ & 0.8596 & 0.9979 & 0.1202 & 0.0819 \\
\hline L_Isoleucine & $124.6 \pm 44.1$ & $113.8 \pm 33.2$ & $149.7 \pm 55.2$ & $161.5 \pm 68.7$ & $111.5 \pm 32.8$ & $114.5 \pm 36.7$ & 0.8596 & 0.9979 & 0.0467 & 0.1621 \\
\hline$\overline{\mathrm{L}}$ _Lysine & $169.4 \pm 36.1$ & $160.3 \pm 28.8$ & $202.1 \pm 61.7$ & $200.5 \pm 48.4$ & $176.8 \pm 39.7$ & $159.3 \pm 36.6$ & 0.8596 & 0.9979 & 0.0903 & 0.1133 \\
\hline L Methionine & $31.9 \pm 7.8$ & $28.5 \pm 5.8$ & $32.9 \pm 10.1$ & $33.3 \pm 7.6$ & $30.7 \pm 9.2$ & $27.6 \pm 8.6$ & 0.8769 & 0.9979 & 0.2812 & 0.2696 \\
\hline L Phenylalanine & $63.7 \pm 12.2$ & $57.3 \pm 9.5$ & $81.6 \pm 21.2$ & $76.9 \pm 15.3$ & $84.9 \pm 41.7$ & $68.4 \pm 13.4$ & 0.8596 & 0.9979 & 0.0015 & 0.4377 \\
\hline L_Threonine & $164.7 \pm 56.4$ & $166.6 \pm 39.5$ & $142.8 \pm 46.6$ & 147. \pm 38.1 & $134.2 \pm 39.7$ & $120.5 \pm 30.1$ & 0.7546 & 0.9979 & 0.0098 & 0.2607 \\
\hline
\end{tabular}

${ }^{1}$ Mean \pm SD, ${ }^{2}$ FDR-adjusted $p$ values.

None of the individual essential amino acids had a significant impact on changes in growth $\mathrm{Z}$ scores from 5 to 12 months of age. When using principal component analysis to further assess the relationship between the essential amino acids and growth Z scores, PC2 was heavily weighted by BCAAs (leucine, isoleucine, valine) and phenylalanine, and had a significant association with LAZ. This principal component had a positive association with changes in LAZ from 5 to 12 months $\left(P_{F D R}=0.0815, P_{\text {raw }}=0.010\right)$ when controlling for diet group but not considering a PC vs. group interaction term. Inclusion of the interaction term resulted in a nominally significant PC2 vs. group interaction $\left(P_{F D R}=0.3883, P_{\text {raw }}=0.0485\right)$ showing that the effect of PC2 was stronger in the meat group (0.346) compared with dairy (0.050). PC2 was not significantly associated with WAZ or WLZ changes regardless of the inclusion of an interaction term $\left(P_{\text {raw }}=0.1286\right.$ and $P_{\text {raw }}=0.7$, respectively for the models without an interaction term).

\subsection{Acylcarnitines \& TMAO (Quantitative)}

Concentrations of acylcarnitine-C4 $\left(P_{F D R}=0.0467, P_{\text {raw }}=0.0140\right)$, acylcarnitine-C5 $\left(P_{F D R}=0.0136, P_{\text {raw }}=0.0034\right)$, and acylcarnitine-C5:1 $\left(P_{F D R}=0.0040, P_{\text {raw }}=0.0005\right)$ significantly increased from 5 to 12 months of age among all participants without statistically significant differences between groups (unadjusted $p$-values of $0.0999,0.3541$ and 0.6493 , respectively. See Table 3 for full results). From 12 to 24 months of age, acylcarnitine-C4 decreased in both groups $(p=0.0045)$. None of the acylcarnitines were associated with infant growth $\mathrm{Z}$ scores. In the model containing both dairy and meat intervention groups, concentrations of TMAO were not significantly different between meat and dairy groups $\left(P_{F D R}=0.7546\right)$ and did not change significantly over time from 5 to 12 months $\left(P_{F D R}=0.4147, P_{\text {raw }}=0.2851\right)$ or from 12 to 24 months $\left(P_{F D R}=0.7800\right.$, $P_{\text {raw }}=0.7750$ ) and were not significantly associated with infant growth $\mathrm{Z}$ scores (FDR adjusted $p$-values for LAZ, WAZ, WLZ, and HCAZ of 0.6168, 0.6251, 0.9920 and 0.5962, respectively). However, in the meat only stratified analysis, TMAO significantly increased from 5 to 12 months $\left(P_{F D R}=0.0414, P_{\text {raw }}=0.0049\right)$. 
Table 3. Concentrations of acylcarnitines $(\mu \mathrm{M})$ and TMAO at 5, 12 and 24 months between the meat and dairy groups ${ }^{1}$.

\begin{tabular}{|c|c|c|c|c|c|c|c|c|c|c|}
\hline \multirow[b]{2}{*}{ Acyl Carnitines } & \multirow[b]{2}{*}{$\begin{array}{c}\text { Meat } \\
5 \mathrm{~m}\end{array}$} & \multirow[b]{2}{*}{$\begin{array}{l}\text { Dairy } \\
5 \mathrm{~m}\end{array}$} & \multirow[b]{2}{*}{$\begin{array}{l}\text { Meat } \\
12 \mathrm{~m}\end{array}$} & \multirow[b]{2}{*}{$\begin{array}{l}\text { Dairy } \\
12 \mathrm{~m}\end{array}$} & \multirow[b]{2}{*}{$\begin{array}{l}\text { Meat } \\
24 \mathrm{~m}\end{array}$} & \multirow[b]{2}{*}{$\begin{array}{l}\text { Dairy } \\
24 \mathrm{~m}\end{array}$} & \multicolumn{4}{|c|}{$\begin{array}{c}\text { Meat Vs. Dairy } \\
\text { Change over Time }\end{array}$} \\
\hline & & & & & & & $12-5$ & 24-12 & $12-5$ & 24-12 \\
\hline TMAO & $0.79 \pm 0.99$ & $1.46 \pm 0.91$ & $1.80 \pm 1.70$ & $1.42 \pm 1.15$ & $1.36 \pm 1.18$ & $1.21 \pm 0.65$ & 0.7546 & 0.9979 & 0.4147 & $\begin{array}{l}0.8000 \\
02882\end{array}$ \\
\hline $\begin{array}{l}\text { 1MAU (meat only) } \\
\text { Acyl-C8:1 }\end{array}$ & $0.34 \pm 0.14$ & $0.31 \pm 0.16$ & $0.24 \pm 0.16$ & $0.33 \pm 0.15$ & $0.14 \pm 0.08$ & $0.13 \pm 0.11$ & 0.9064 & 0.9979 & $\begin{array}{l}0.0431 \\
0.3122\end{array}$ & $\begin{array}{l}0.2882 \\
0.0901\end{array}$ \\
\hline Acyl-C8 & $0.14 \pm 0.06$ & $0.12 \pm 0.05$ & $0.10 \pm 0.06$ & $0.12 \pm 0.07$ & $0.07 \pm 0.05$ & $0.07 \pm 0.04$ & 0.8596 & 0.9979 & 0.5238 & 0.2112 \\
\hline Acyl- C6 & $0.06 \pm 0.02$ & $0.05 \pm 0.02$ & $0.04 \pm 0.02$ & $0.05 \pm 0.02$ & $0.02 \pm 0.01$ & $0.02 \pm 0.01$ & 0.8596 & 0.9979 & 0.0903 & 0.0912 \\
\hline Acyl-C5:1 & $0.006 \pm 0.003$ & $0.006 \pm 0.003$ & $0.009 \pm 0.005$ & $0.012 \pm 0.005$ & $0.011 \pm 0.003$ & $0.008 \pm 0.01$ & 0.8596 & 0.9979 & 0.0040 & 0.5416 \\
\hline Acyl-C5 & $0.13 \pm 0.06$ & $0.11 \pm 0.05$ & $0.14 \pm 0.10$ & $0.16 \pm 0.10$ & $0.16 \pm 0.09$ & $0.11 \pm 0.05$ & 0.8596 & 0.9979 & 0.0136 & 0.1850 \\
\hline Acyl-C4 & $0.21 \pm 0.11$ & $0.22 \pm 0.07$ & $0.22 \pm 0.11$ & $0.24 \pm 0.13$ & $0.22 \pm 0.06$ & $0.15 \pm 0.05$ & 0.7546 & 0.8726 & 0.0467 & 0.0045 \\
\hline Aycl-C3 & $0.59 \pm 0.18$ & $0.61 \pm 0.20$ & $0.62 \pm 0.26$ & $0.68 \pm 0.32$ & $0.56 \pm 0.17$ & $0.46 \pm 0.17$ & 0.9990 & 0.9979 & 0.3122 & 0.1137 \\
\hline Acyl-C2 & $11.92 \pm 4.06$ & $12.92 \pm 3.01$ & $9.76 \pm 5.76$ & $11.41 \pm 4.36$ & $7.34 \pm 2.06$ & $7.29 \pm 2.20$ & 0.8596 & 0.9979 & 0.1427 & 0.0819 \\
\hline Acyl-C10:1 & $0.11 \pm 0.06$ & $0.12 \pm 0.05$ & $0.09 \pm 0.06$ & $0.13 \pm 0.07$ & $0.04 \pm 0.03$ & $0.06 \pm 0.04$ & 0.8596 & 0.9979 & 0.9111 & 0.0986 \\
\hline Acyl-C10 & $0.10 \pm 0.09$ & $0.12 \pm 0.06$ & $0.08 \pm 0.08$ & $0.11 \pm 0.10$ & $0.05 \pm 0.06$ & $0.06 \pm 0.06$ & 0.8596 & 0.9979 & 0.9111 & 0.3996 \\
\hline Acyl-C12 & $0.12 \pm 0.13$ & $0.15 \pm 0.07$ & $0.09 \pm 0.08$ & $0.14 \pm 0.11$ & $0.06 \pm 0.07$ & $0.09 \pm 0.11$ & 0.8596 & 0.9979 & 0.5238 & 0.7337 \\
\hline Acyl-C12:1 & $0.05 \pm 0.07$ & $0.07 \pm 0.05$ & $0.05 \pm 0.06$ & $0.07 \pm 0.07$ & $0.06 \pm 0.06$ & $0.08 \pm 0.05$ & 0.9723 & 0.9979 & 0.9111 & 0.8219 \\
\hline
\end{tabular}

\subsection{Untargeted Metabolomics}

Overall, 151 metabolites were annotated by the untargeted metabolomics analysis in both hydrophilic and hydrophobic modes. Consistent with the targeted analysis, threonine decreased $\left(P_{F D R}=0.0037, P_{\text {raw }}<0.0001\right)$ and valine increased $\left(P_{F D R}=0.0205\right.$, $\left.P_{\text {raw }}=0.0002\right)$ from 5 to 12 months without differences between groups (unadjusted $p$-values of 0.0594 and 0.8713 , respectively). Acylcarnitine-C5 $\left(P_{F D R}=0.0205, P_{\text {raw }}=0.0003\right)$ and acylcarnitine-C5:1 $\left(P_{F D R}=0.0012, P_{\text {raw }}<0.0001\right)$ also increased from 5 to 12 months in both groups. There were no significant changes of the metabolites from 12 to 24 months. We also ran the association of gender and change in metabolite for both targeted and untargeted data. When we adjust for multiple tests, none of the metabolites passed a FDR $p$ value of 0.05 .

\section{Discussion}

This study aimed to identify metabolites in serum that are associated with consuming the meat- and dairy-based complementary diet and infant growth. We found that consuming a high-protein complementary diet ( $\sim 15 \%$ of total energy) significantly increased serum concentrations of several essential amino acids, including phenylalanine, BCAA isoleucine, and valine from baseline ( $10 \%$ of total energy from protein). These findings were expected because all participants increased their protein intake from $2.1 \mathrm{~g} / \mathrm{kg} / \mathrm{d}$ to $3.2 \mathrm{~g} / \mathrm{kg} / \mathrm{d}$ from 5 to 12 months of age [10]. One adult cohort showed that habitually consuming meat, fish and vegetarian-based diets led to significantly different concentrations of circulating essential amino acids, which were associated with dietary protein quality and quantity [16]. A number of intervention studies also reported that plasma essential amino acid concentrations depend upon dietary protein quality, with higher essential amino acid concentrations associated with animal protein intakes $[17,18]$. In our study, we did not observe significant differences in relative metabolite amounts between the meat and dairy groups. Because both meat and dairy foods are considered high-quality protein sources according to the WHO digestible indispensable amino acid score, consuming the same quantity likely contributed to comparable circulating amino acid profiles as shown in our study.

Insulin-like growth factor I (IGF-1) has been proposed to be the key mediator of WLZ difference found between groups consuming a high- vs. low-protein infant formula [19]. This concept is also called the "early protein hypothesis" [20]. In our study, infants from both the meat- and dairy-groups gained comparable amounts of weight, which were consistent with similar increases in IGF-1 concentrations in both groups [10]. Thus, differences in IGF-1 concentrations between meat and dairy groups did not explain the distinctive length gain in the meat group compared to dairy group (e.g., LAZ). We also ran the same models for the untargeted metabolomics data with change in IGF-1 value as the outcome, but none of the metabolites passes an FDR of 0.05. Although none of the individual amino acids 
were associated with growth $\mathrm{Z}$ scores of the participants, there was a nominally significant positive association between the BCAAs and phenylalanine principal component (PC2) with LAZ. This could suggest that protein-rich foods high in BCAAs and phenylalanine may promote infant linear growth. However, more research is needed to directly assess the potential impact of BCAAs on infant linear growth. Besides the potential effect of increasing insulin and IGF-1, BCAAs, especially leucine, have been considered potent nutrient signals to induce muscle synthesis [21] and bone density [22,23]. This may partially contribute to the association of BCAAs and LAZ in our study. Although a number of previous studies have reported that high quality, animal-based protein improves linear growth in infants and young children at risk of growth faltering from low-resource settings [24,25], it is still not clear how the sources of animal-based protein, such as meat and dairy, could differentially impact infant growth trajectories. Moreover, although dairy foods, especially whey protein, tend to have higher BCAA contents compared with meat [26], some research in overweight adults reported that meat intake was associated with higher BCAA concentrations while dairy was not [27]. It is also possible that constituents beyond protein in these protein-rich foods, such as vitamins and minerals, could potentially affect infant growth and weight gain, and that it is not protein but other compounds in protein-rich foods that could affect infant growth. For example, meat and dairy foods also had strikingly different iron contents. Because other diet-induced changes, such as gut microbiota, could be a potential mediator of dietary protein and infant growth [28] and iron is a key nutrient that could modulate developing gut microbiota [29]. These speculations clearly require further investigation. Nonetheless, these compounds in meat and dairy-rich foods are still integral parts of the whole foods, and findings are valid in terms of dietary patterns on infant growth and risk of overweight, especially when these dietary patterns during the first year of life had lasting effects.

We found an increase in short-chain acyl-carnitine concentrations (C4 and C5) from 5 to 12 months without group differences. Acyl-carnitines are fatty acid oxidation intermediates and short-chain acyl-carnitines can be produced as part of BCAA degrading products [30]. These findings were consistent with a previous study in 6-month-old infants showing that C4- and C5-acylcarnitines increased with high-protein formula consumption [3]. These short-chain acyl-carnitines have been found to associate with insulin resistance in adults [30], but the effects in infants are not clear. Short-chain acyl-carnitines are also emerging as a generic indicator of meat intake [31], although the concentrations increased in both meat and dairy groups in our study. We did not find any changes over time in long-chain acyl-carnitines, which are considered an indicator of fatty-acid oxidation and are reportedly higher in obese adults [32]. TMAO, a molecule generated from choline, betaine, and carnitine via gut microbial metabolism, is emerging as a potent biomarker for cardiovascular disease and strongly associated with meat intake [33]. However, most of the research on TMAO and meat intake has been conducted in adults. In our study, the meat group significantly increased protein intake from 5 to 12 months and the primary source of protein from complementary foods was meat; TMAO did not increase significantly from 5 to 12 months in the meat group, not dairy. However, TMAO concentrations dropped from 12 to 24 months as the intervention ended at 12 months. Thus, the long-term impact of meat intake on infant's cardiovascular function and the biological significance of TMAO during infancy require further investigation.

There are several limitations of this study. First, we had a relatively small sample size and power calculation was based on the primary outcome infant growth. It is possible that we were underpowered for the metabolomics analysis. Second, only formula-fed infants were studied which reduced the generalizability of the findings. Third, we did not include a "reference" or "control" group without dietary protein intervention, although it is challenging to define a standard complementary diet since recommendations are generally lacking. 


\section{Conclusions}

Overall, our findings suggest that increasing total protein intake from $\sim 2 \mathrm{~g} / \mathrm{kg} / \mathrm{d}$ at 5 months to $3.2 \mathrm{~g} / \mathrm{kg} / \mathrm{d}$ by providing protein-rich complementary foods was associated with increased concentrations of certain essential amino acids and short-chain acyl-carnitines. The sources of protein-rich foods (e.g., meat vs. dairy) did not appear to differentially impact serum metabolites. In addition, serum BCAAs may at least partially contribute to infant linear growth during complementary feeding. Future comprehensive mechanistic investigations are needed to identify other contributors or mediators of the diet-induced infant growth trajectories.

Author Contributions: Conceptualization, M.T. and N.F.K.; methodology, M.T. and N.F.K.; formal analysis, N.E.W., M.T. and A.E.H.; data curation, M.T., L.M.B.; writing M.T., N.E.W., L.M.B., L.D.B., A.E.H., N.F.K.; project administration, M.T. and N.F.K.; funding acquisition, M.T. and N.F.K. All authors have read and agreed to the published version of the manuscript.

Funding: NIH (NIDDK) 1K01DK111665-01, NIH/NCATS Colorado CTSA Grant Number UL1 TR001082 and (alphabetically) Abbott Nutrition, the American Heart Association, the Beef Checkoff through the National Cattlemen's Beef Association, Leprino foods, the National Pork Board.

Institutional Review Board Statement: The study was conducted according to the guidelines of the Declaration of Helsinki, and approved by the Colorado Multiple Institutional Review Board (protocol code 14-0139, March 2014).

Informed Consent Statement: Informed consent was obtained from all subjects involved in the study.

Data Availability Statement: The data presented in this study are available from the authors.

Acknowledgments: We thank all the participants and their families for their support of this study.

Conflicts of Interest: The authors declare no conflict of interest.

\section{References}

1. Brisbois, T.D.; Farmer, A.P.; McCargar, L.J. Early markers of adult obesity: A review. Obes. Rev. 2012, 13, 347-367. [CrossRef] [PubMed]

2. Dewey, K.G.; Heinig, M.J.; Nommsen, L.A.; Peerson, J.M.; Lonnerdal, B. Growth of breast-fed and formula-fed infants from 0 to 18 months: The DARLING Study. Pediatrics 1992, 89, 1035-1041. [PubMed]

3. Koletzko, B.; von Kries, R.; Closa, R.; Escribano, J.; Scaglioni, S.; Giovannini, M.; Beyer, J.; Demmelmair, H.; Gruszfeld, D.; Dobrzanska, A.; et al. Lower protein in infant formula is associated with lower weight up to age $2 \mathrm{y}$ : A randomized clinical trial. Am. J. Clin. Nutr. 2009, 89, 1836-1845. [PubMed]

4. Turck, D.; Grillon, C.; Lachambre, E.; Robiliard, P.; Beck, L.; Maurin, J.L.; Kempf, C.; Bernet, J.P.; Marx, J.; Lebrun, F.; et al. Adequacy and safety of an infant formula with a protein/energy ratio of $1.8 \mathrm{~g} / 100 \mathrm{kcal}$ and enhanced protein efficiency for term infants during the first 4 months of life. J. Pediatr. Gastroenterol. Nutr. 2006, 43, 364-371. [CrossRef]

5. Fewtrell, M.; Bronsky, J.; Campoy, C.; Domellof, M.; Embleton, N.; Fidler Mis, N.; Hojsak, I.; Hulst, J.M.; Indrio, F.; Lapillonne, A.; et al. Complementary Feeding: A Position Paper by the European Society for Paediatric Gastroenterology, Hepatology, and Nutrition (ESPGHAN) Committee on Nutrition. J. Pediatr. Gastroenterol. Nutr. 2017, 64, 119-132. [CrossRef]

6. Roess, A.A.; Jacquier, E.F.; Catellier, D.J.; Carvalho, R.; Lutes, A.C.; Anater, A.S.; Dietz, W.H. Food Consumption Patterns of Infants and Toddlers: Findings from the Feeding Infants and Toddlers Study (FITS) 2016. J. Nutr. 2018, 148, 1525S-1535S. [CrossRef]

7. Turner, K.M.; Keogh, J.B.; Clifton, P.M. Red meat, dairy, and insulin sensitivity: A randomized crossover intervention study. Am. J. Clin. Nutr. 2015, 101, 1173-1179. [CrossRef]

8. Rohrmann, S.; Platz, E.A.; Kavanaugh, C.J.; Thuita, L.; Hoffman, S.C.; Helzlsouer, K.J. Meat and dairy consumption and subsequent risk of prostate cancer in a US cohort study. Cancer Causes Control 2007, 18, 41-50. [CrossRef]

9. Tang, M.; O'Connor, L.E.; Campbell, W.W. Diet-induced weight loss: The effect of dietary protein on bone. J. Acad. Nutr. Diet. 2014, 114, 72-85. [CrossRef]

10. Tang, M.; Hendricks, A.E.; Krebs, N.F. A meat- or dairy-based complementary diet leads to distinct growth patterns in formula-fed infants: A randomized controlled trial. Am. J. Clin. Nutr. 2018, 107, 734-742. [CrossRef]

11. Tang, M.; Andersen, V.; Hendricks, A.E.; Krebs, N.F. Different Growth Patterns Persist at 24 Months of Age in Formula-Fed Infants Randomized to Consume a Meat- or Dairy-Based Complementary Diet from 5 to 12 Months of Age. J. Pediatr. 2019, 206, 78-82. [CrossRef] [PubMed]

12. Kirchberg, F.F.; Harder, U.; Weber, M.; Grote, V.; Demmelmair, H.; Peissner, W.; Rzehak, P.; Xhonneux, A.; Carlier, C.; Ferre, N.; et al. Dietary protein intake affects amino acid and acylcarnitine metabolism in infants aged 6 months. J. Clin. Endocrinol. Metab. 2015, 100, 149-158. [CrossRef] [PubMed] 
13. Gehrke, S.; Rice, S.; Stefanoni, D.; Wilkerson, R.B.; Nemkov, T.; Reisz, J.A.; Hansen, K.C.; Lucas, A.; Cabrales, P.; Drew, K.; et al. Red Blood Cell Metabolic Responses to Torpor and Arousal in the Hibernator Arctic Ground Squirrel. J. Proteome Res. 2019, 18, 1827-1841. [CrossRef] [PubMed]

14. Nemkov, T.; D'Alessandro, A.; Hansen, K.C. Three-minute method for amino acid analysis by UHPLC and high-resolution quadrupole orbitrap mass spectrometry. Amino Acids 2015, 47, 2345-2357. [CrossRef] [PubMed]

15. McCurdy, C.E.; Schenk, S.; Hetrick, B.; Houck, J.; Drew, B.G.; Kaye, S.; Lashbrook, M.; Bergman, B.C.; Takahashi, D.L.; Dean, T.A.; et al. Maternal obesity reduces oxidative capacity in fetal skeletal muscle of Japanese macaques. JCI Insight 2016, 1, e86612. [CrossRef] [PubMed]

16. Schmidt, J.A.; Rinaldi, S.; Scalbert, A.; Ferrari, P.; Achaintre, D.; Gunter, M.J.; Appleby, P.N.; Key, T.J.; Travis, R.C. Plasma concentrations and intakes of amino acids in male meat-eaters, fish-eaters, vegetarians and vegans: A cross-sectional analysis in the EPIC-Oxford cohort. Eur. J. Clin. Nutr. 2016, 70, 306-312. [CrossRef]

17. Liu, J.; Klebach, M.; Visser, M.; Hofman, Z. Amino Acid Availability of a Dairy and Vegetable Protein Blend Compared to Single Casein, Whey, Soy, and Pea Proteins: A Double-Blind, Cross-Over Trial. Nutrients 2019, 11, 2613. [CrossRef]

18. Markova, M.; Pivovarova, O.; Hornemann, S.; Sucher, S.; Frahnow, T.; Wegner, K.; Machann, J.; Petzke, K.J.; Hierholzer, J.; Lichtinghagen, R.; et al. Isocaloric Diets High in Animal or Plant Protein Reduce Liver Fat and Inflammation in Individuals With Type 2 Diabetes. Gastroenterology 2017, 152, 571-585. [CrossRef]

19. Socha, P.; Grote, V.; Gruszfeld, D.; Janas, R.; Demmelmair, H.; Closa-Monasterolo, R.; Subias, J.E.; Scaglioni, S.; Verduci, E.; Dain, E.; et al. Milk protein intake, the metabolic-endocrine response, and growth in infancy: Data from a randomized clinical trial. Am. J. Clin. Nutr. 2011, 94, 1776S-1784S.

20. Luque, V.; Closa-Monasterolo, R.; Escribano, J.; Ferre, N. Early Programming by Protein Intake: The Effect of Protein on Adiposity Development and the Growth and Functionality of Vital Organs. Nutr. Metab. Insights 2015, 8, 49-56. [CrossRef]

21. Shimomura, Y.; Yamamoto, Y.; Bajotto, G.; Sato, J.; Murakami, T.; Shimomura, N.; Kobayashi, H.; Mawatari, K. Nutraceutical effects of branched-chain amino acids on skeletal muscle. J. Nutr. 2006, 136, 529S-532S. [CrossRef] [PubMed]

22. Jennings, A.; MacGregor, A.; Spector, T.; Cassidy, A. Amino Acid Intakes Are Associated With Bone Mineral Density and Prevalence of Low Bone Mass in Women: Evidence from Discordant Monozygotic Twins. J. Bone Miner. Res. 2016, 31, $326-335$. [CrossRef] [PubMed]

23. Ammann, P.; Laib, A.; Bonjour, J.P.; Meyer, J.M.; Ruegsegger, P.; Rizzoli, R. Dietary essential amino acid supplements increase bone strength by influencing bone mass and bone microarchitecture in ovariectomized adult rats fed an isocaloric low-protein diet. J. Bone Miner. Res. 2002, 17, 1264-1272. [CrossRef] [PubMed]

24. Kaimila, Y.; Divala, O.; Agapova, S.E.; Stephenson, K.B.; Thakwalakwa, C.; Trehan, I.; Manary, M.J.; Maleta, K.M. Consumption of Animal-Source Protein is Associated with Improved Height-for-Age z Scores in Rural Malawian Children Aged 12(-)36 Months. Nutrients 2019, 11, 480. [CrossRef]

25. Tang, M.; Sheng, X.Y.; Krebs, N.F.; Hambidge, K.M. Meat as complementary food for older breastfed infants and toddlers: A randomized, controlled trial in rural China. Food Nutr. Bull. 2014, 35, S188-S192. [CrossRef]

26. Millward, D.J.; Layman, D.K.; Tome, D.; Schaafsma, G. Protein quality assessment: Impact of expanding understanding of protein and amino acid needs for optimal health. Am. J. Clin. Nutr. 2008, 87, 1576S-1581S. [CrossRef]

27. Rousseau, M.; Guenard, F.; Garneau, V.; Allam-Ndoul, B.; Lemieux, S.; Perusse, L.; Vohl, M.C. Associations Between Dietary Protein Sources, Plasma BCAA and Short-Chain Acylcarnitine Levels in Adults. Nutrients 2019, 11, 173. [CrossRef]

28. Blanton, L.V.; Charbonneau, M.R.; Salih, T.; Barratt, M.J.; Venkatesh, S.; Ilkaveya, O.; Subramanian, S.; Manary, M.J.; Trehan, I.; Jorgensen, J.M.; et al. Gut bacteria that prevent growth impairments transmitted by microbiota from malnourished children. Science 2016, 351, 6275. [CrossRef]

29. Jaeggi, T.; Kortman, G.A.; Moretti, D.; Chassard, C.; Holding, P.; Dostal, A.; Boekhorst, J.; Timmerman, H.M.; Swinkels, D.W.; Tjalsma, H.; et al. Iron fortification adversely affects the gut microbiome, increases pathogen abundance and induces intestinal inflammation in Kenyan infants. Gut 2015, 64, 731-742. [CrossRef]

30. Newgard, C.B. Interplay between lipids and branched-chain amino acids in development of insulin resistance. Cell Metab. 2012, 15, 606-614. [CrossRef]

31. Cheung, W.; Keski-Rahkonen, P.; Assi, N.; Ferrari, P.; Freisling, H.; Rinaldi, S.; Slimani, N.; Zamora-Ros, R.; Rundle, M.; Frost, G.; et al. A metabolomic study of biomarkers of meat and fish intake. Am. J. Clin. Nutr. 2017, 105, 600-608. [CrossRef] [PubMed]

32. Mihalik, S.J.; Goodpaster, B.H.; Kelley, D.E.; Chace, D.H.; Vockley, J.; Toledo, F.G.; DeLany, J.P. Increased levels of plasma acylcarnitines in obesity and type 2 diabetes and identification of a marker of glucolipotoxicity. Obesity 2010, 18, 1695-1700. [CrossRef] [PubMed]

33. Wang, Z.; Bergeron, N.; Levison, B.S.; Li, X.S.; Chiu, S.; Jia, X.; Koeth, R.A.; Li, L.; Wu, Y.; Tang, W.H.W.; et al. Impact of chronic dietary red meat, white meat, or non-meat protein on trimethylamine N-oxide metabolism and renal excretion in healthy men and women. Eur. Heart J. 2019, 40, 583-594. [CrossRef] [PubMed] 